\title{
Os AFETOS DO ANALISTA NA OBRA FREUDIANA
}

\author{
Ana Bárbara de Toledo Andrade* \\ Regina Herzog**
}

\section{Resumo}

Este artigo tem como objetivo discutir a posição de Freud quanto ao lugar dos afetos do analista na clínica psicanalítica. Isto será feito através da verificação de escritos técnicos, nos quais se depreende uma distinção entre atuação da contratransferência e sua elaboração (dois destinos possíveis para o afeto do analista). Além disso, busca-se apresentar uma análise hermenêutica do termo alemão bewältigen. Este é empregado por Freud para se referir, neste contexto particular, à atividade do analista diante da contratransferência. Este termo é traduzido por "sobrepujar" no artigo "As perspectivas futuras da terapêutica psicanalítica". Por fim, hipotetiza-se, com base nessas consideraçôes, que o texto freudiano dá margem a uma perspectiva positiva quanto à afetividade do analista na experiência psicanalítica.

Palavras-chave: função do analista; afetos; contratransferência; técnica.

\section{Abstracts}

The ANALYST'S AFFECTS IN FREUdian WORK

This article intends to discuss the Freud's position relative to the place of the analyst's affects in psychoanalysis practice. From the examination of technical articles, we can infer a distinction between the acting-out of counter-transference and its elaboration (two possible destinies for the analyst's affect). It is also presented an hermeneutical reflection on the German term bewältigen, used by Freud in this particular context to refer to the analyst's activity when dealing with counter-transference, term witch was translated to "to overcome" in the article "The future chances of psychoanalytic therapy". From these considerations, we advocate the hypothesis

* Mestre em Teoria Psicanalítica pela Universidade Federal do Rio de Janeiro (UFRJ); Doutoranda do Programa de Pós-Graduação em Teoria Psicanalítica da UFRJ.

** Professora Associada do Programa de Pós-Graduação em Teoria Psicanalítica da Universidade Federal do Rio de Janeiro (UFRJ); Bolsista de Produtividade em Pesquisa do CNPq. 
that the Freudian text allows a positive perspective about analyst's affect manifestation in the psychoanalysis experience.

Keywords: analyst's function; affects; counter-transference; technique.

\section{INTRODUÇÃo}

Atualmente a literatura psicanalítica mostra uma crescente valorização do aspecto afetivo da função analítica. Esta, por sua vez, se dá em detrimento de uma postura racional e objetiva do analista. A figura do analista neutro e inacessível - imagem pouco lisonjeira, através da qual o psicanalista foi sempre representado em charges e anedotas - vem dando lugar, pelo menos no que diz respeito ao campo psicanalítico, ao reconhecimento de que a função analítica é exercida a partir do encontro afetivo com o paciente. Com isto, nos deparamos com uma ampla discussão sobre a importância dos aspectos afetivos em jogo na relação transferencial, o que implica tanto o analisando quanto o analista.

A ênfase na positividade dos afetos do analista está associada à própria especificidade do contexto clínico na atualidade. Diante das formas atuais de sofrimento psíquico, a técnica psicanalítica clássica vem sendo colocada em questão. Um aspecto marcante, como se assinala com frequência sobre os pacientes contemporâneos, é a dificuldade no processo de simbolização e de produção fantasmática. Além disso, observa-se certa anestesia afetiva que os impede de entrar em contato com seus sentimentos e emoções. A interpretação, como dispositivo clínico, vem sendo considerada insuficiente para dar conta desta especificidade da clínica contemporânea. Entre as perguntas que surgem, destacamos: como o analista deve interpretar uma fala desafetada? Dada a dificuldade do paciente em expressar suas sensações e emoções, de que modo o analista pode conduzir o tratamento? Assim, se por um lado a técnica interpretativa vem perdendo seu lugar de excelência, por outro a vivência emocional do analista vem despontando como um aspecto a ser levado em conta no dispositivo clínico, na medida em que sua sensibilidade afetiva parece ser cada vez mais requisitada.

Quanto a esta questão, é frequente observar um posicionamento teórico-clínico que ressalta a incompatibilidade entre a perspectiva clínica de Freud - designada como clássica - e a demanda da clínica contemporânea. O que se argumenta é que Freud teria se voltado ao tratamento de pacientes não muito graves, os quais não demandavam necessariamente a participação afetiva do analista. E o mesmo não ocorreria com os pacientes atuais. Segundo esta perspectiva, a experiência clínica de Freud o levou a desenvolver recomendações técnicas que remetem à supressão 
radical do afeto ${ }^{1}$ por parte do analista. A vivência afetiva teria sido considerada desnecessária ou mesmo prejudicial à condução do tratamento.

Por outro lado, autores como Ferenczi e Winnicott, cuja experiência clínica

é notoriamente marcada por casos difíceis, tornaram-se as maiores referências na clínica contemporânea. Isto marca certa polaridade entre a perspectiva clássica freudiana e a nova perspectiva clínica. Nesta oposição, Freud é considerado o defensor da assepsia afetiva do analista. Já Ferenczi e Winnicott são vistos como os pioneiros no reconhecimento da importância dos afetos do analista no contexto clínico. Frente a esta suposta polaridade, nos questionamos se a perspectiva clínica freudiana se distanciaria tão radicalmente das proposições teórico-clínicas desenvolvidas posteriormente.

\section{Os afetos do analista em Freud}

A nosso ver, a posição freudiana em relação à afetividade do analista, ao contrário do que se costuma supor, não se mostra tão rigorosamente asséptica. Nossa hipótese é a de que o texto freudiano dá margem a uma interpretação diversa sobre esta questão. Embora Freud tenha alertado para o perigo representado pelas respostas afetivas, despertadas na relação transferencial, é possível observar que ele deixa implícita uma perspectiva mais favorável quanto aos afetos do analista. Para tanto, vamos nos debruçar sobre os escritos técnicos de Freud a fim de examinar sua posição com relação à função analítica. A análise do conceito de contratransferência demonstrará que, no texto freudiano, a implicação afetiva do analista comporta, sim, uma dimensão positiva.

\section{O LUGAR doS AFETOS DO ANALISTA NA TÉCNICA}

Para começar, é importante lembrar que, para Freud, a experiência de analisar é atravessada pelo campo afetivo do analista. Isto fica patente quando reconhece que todo analista, no exercício de sua função, está submetido aos efeitos do encontro com seu paciente - encontro do qual não poderia escapar ileso (Freud, [1905] 1980). Advertiu, ainda, para o fato inevitável de que, ao manejar as forças pulsionais do analisando, os afetos, conflitos e fantasias do analista acabariam por ser despertados. Isto impõe a necessidade de se posicionar frente à emergência de suas próprias forças pulsionais com vistas a lhes dar algum destino (Freud, [1937a] 1980). 
Tradicionalmente, considera-se que o destino sugerido por Freud para a vivência afetiva do analista seria: a supressão deste elemento perturbador ao ofício analítico. No entanto, ao longo dos artigos que tratam da técnica psicanalítica, nas diferentes fases de sua elaboração teórica, é possível vislumbrar uma leitura que contrasta com esta visada. Embora o autor aponte os riscos da emergência dessa afetividade, sua preocupação não o impede de reconhecer que o analista exerce sua função sob o domínio de suas pulsões e afetos.

Não se pode negar que a leitura apressada de "Recomendações aos médicos que exercem a psicanálise" (Freud, [1912] 1980) permite a interpretação de que Freud estaria levantando, sem concessões, a bandeira da assepsia psíquica do analista. A imagem do cirurgião, metáfora para o trabalho do analista, decerto comporta a ideia de uma defesa da objetividade da função analítica. Embora ele se refira, no início do texto, à necessidade de "frieza emocional" (Freud, [1912] 1980: 153) por parte do analista, essa posição não se sustenta ao longo de todo o artigo.

Ao mesmo tempo que o autor compara o trabalho do analista ao do cirurgião - subentendendo que o analista deve neutralizar seus sentimentos -, em outra passagem, quando se refere à regra da atenção flutuante, depreende-se a possibilidade de o analista envolver-se afetivamente no trabalho psicanalítico. Vejamos a seguir como isto aparece.

A regra da atenção flutuante é descrita como um estado no qual o analista mantém uma atenção uniformemente suspensa frente a tudo o que escuta. $\mathrm{Ou}$ seja, não dirige sua atenção para nada específico; sem expectativas nem inclinações. Para cumprir esta regra, o analista busca dominar as influências conscientes da sua capacidade de prestar atenção, abandonando inteiramente a "memória inconsciente" (Freud, [1912] 1980: 150) do analista.

Deste modo, como sugere Viderman (1990), Freud organiza o campo analítico formado por duas correntes de memórias inconscientes: (1) do lado do paciente: a associação livre; (2) do lado do analista: a atenção flutuante. No que concerne à primeira corrente, Freud insiste que a condição de possibilidade de emergência do material inconsciente do analisando é a obediência à regra da associação livre. Em linhas gerais, sugere-se que, ao se entregar à livre associação, conteúdos inconscientes viriam à tona para serem trabalhados em análise. Quando esses conteúdos inconscientes emergem, o afeto ligado a eles também pode se expressar - só deste modo, no campo das intensidades afetivas, ao ceder à "vertigem do afeto" (Schneider, 1993: 59), algo pode ser elaborado no trabalho psicanalítico.

Do mesmo modo, por parte do analista, a regra da atenção flutuante permite aflorar, devido ao afrouxamento da vigilância egoica, os conteúdos inconscientes. Dessa forma, abre-se caminho para o afeto ligado a esses conteúdos. Neste sentido, 
a atenção flutuante - descrita como um estado psíquico em que o analista se entrega livremente à atividade de seu próprio inconsciente - tem como consequência certa abertura para as intensidades afetivas no analista, fazendo com que ele se abandone neste mergulho afetivo. Ademais, como acrescenta Freud ([1912] 1980), o estado de atenção flutuante permitiria a comunicação entre inconscientes. Em última análise, este processo indica a possibilidade de um encontro afetivo entre analista e analisando (Gondar, 2008).

Além dessa passagem, a metáfora do espelho empregada por Freud é um bom exemplo quanto ao risco de uma interpretação equivocada do texto freudiano. Esta metáfora traduz a necessidade de o analista ocupar uma posição de tal opacidade diante do analisando que, "como um espelho, não deve mostrar-lhe nada, exceto o que lhe é mostrado" (Freud, [1912] 1980: 157). Certamente é fácil associar a esta metáfora a figura de um analista neutro ou asséptico. Contudo, a imagem do analista-espelho não implica, necessariamente, a exigência de frieza emocional. Ao contrário, o que nos parece mais importante nesta recomendação é a sugestão de que o analista não exponha ao paciente seus próprios sentimentos. Ao invés de falar em neutralidade, ele sugere apenas que o analista seja opaco aos olhos do paciente. A ideia de opacidade deve ser entendida no sentido de que o analista não pode ser transparente quanto a seus afetos. Dessa forma, a opacidade do espelho teria a função de garantir o cumprimento dessa recomendação.

Estas considerações mostram como o lugar do analista no discurso freudiano não ocupa uma posição fixa e imutável. Isso pode ser confirmado, mais uma vez, ao se examinar o desdobramento clínico ocorrido a partir do artigo "Além do princípio do prazer" (Freud, [1920] 1980) e a consequente modificação da tópica freudiana. Os artigos "Construçōes em análise” (Freud, [1937a] 1980) e "Análise terminável e interminável” (Freud, [1937b] 1980), os dois últimos textos freudianos de caráter essencialmente técnicos, apresentam as novas características da prática clínica decorrentes da reformulação teórica de 1920.

Nesta perspectiva, Freud define a tarefa do analista como um trabalho de construção (Freud, [1937a] 1980). Trata-se de construir uma cena, visando completar a história primitiva esquecida do paciente. Suas ideias são extraídas dos fragmentos de lembrança, das associações e também do comportamento do analisando.

Neste texto ([1937a] 1980), Freud afirma que a construção do analista deveria, em tese, se desdobrar numa recordação pelo paciente. Contudo, ele reconhece que o trabalho, em geral, não alcança tal objetivo. Em vez de recordar o material recalcado, produz-se no paciente uma convicção da verdade da construção, tendo como resultado os mesmos efeitos que ocorreriam se o paciente tivesse de fato recordado. Mais do que rememorar seus conflitos, o que importa é o que o pa- 
ciente disso reconstrói ${ }^{2}$. Quanto ao analista, Freud afirma não pretender "que uma construção individual seja algo mais do que uma conjectura que aguarda exame, confirmação ou rejeição. Não reivindicamos autoridade para ela” ([1937a] 1980: 300). Com isso, exorta o analista a criar, a partir das associações do analisando, o processo que implica a presença afetiva do analista. Mas como prescindir de sua afetividade na condução de um trabalho de construção-criação? Ao criar, ele deve servir-se de sua subjetividade, de suas fantasias. Assim, o analista pode deflagrar o processo de invenção em análise - processo que, segundo esta perspectiva, ganha a dimensão de uma aventura imprevisível.

Se, em "Construções em análise", Freud ([1937a] 1980) torna o lugar do analista mais flexível, não se observa a mesma abertura em "Análise terminável e interminável” (Freud, [1937b] 1980). Neste texto contemporâneo, são discutidos os riscos que a subjetividade do analista oferece para o trabalho psicanalítico. Um dos "perigos da análise" (Freud, [1937b] 1980: 283) descritos por Freud é que as próprias exigências pulsionais do analista seriam mais facilmente despertadas ao ter de manejar as pulsóes e o material recalcado de seus analisandos - questão que nos leva necessariamente ao conceito de contratransferência.

\section{QuAl O DESTINO PARA A CONTRATRANSFERÊNCIA?}

A posição mais rígida a respeito do lugar do analista encontrada no texto freudiano, no qual parece não haver abertura para concessões, é aquela relativa ao conceito de contratransferência. Embora as referências ao tema sejam concisas na obra de Freud - há apenas três referências diretas ao conceito -, ele manifestou claramente suas reservas em relação às respostas contratransferenciais na situação analítica. No artigo sobre as perspectivas futuras da terapêutica psicanalítica ([1910a] 1980), Freud formula a noção de contratransferência pela primeira vez. Ela é descrita como o resultado da influência do paciente sobre o inconsciente do analista. A contratransferência é, segundo o autor, negativa e prejudicial ao tratamento, sendo necessário seu domínio. A respeito deste fenômeno, Freud ([1910a] 1980:130) diz: "Estamos quase inclinados a insistir que ele [analista] reconhecerá a contratransferência em si mesmo e a sobrepujará”. Em outra ocasião, recomenda "cautela e autodomínio" ([1912] 1980: 158) por parte do analista. E, mais tarde, no artigo sobre o amor transferencial, reafirma que "não devemos abandonar a neutralidade para com a paciente, que adquirimos por manter controlada a contratransferência” ([1914-1915] 1980: 214). 
Estas três recomendações de Freud são aparentemente simples e se resumem à ideia de que cabe ao analista dominar a contratransferência. Mas o que se subentende na indicação de domínio da contratransferência? Trata-se de buscar suprimi-la, eliminá-la?

Freud parece responder a esta questão de forma enviesada, quando impõe ao analista a necessidade de se submeter a uma autoanálise; só assim o analista conseguiria sobrepujar a contratransferência. Mas será que, com isso, ele estaria, de fato, sugerindo a supressão de qualquer vestígio contratransferencial?

Numa carta endereçada ao psiquiatra suíço Ludwig Binswanger, escrita em 20 de fevereiro de 1913, sua posição sobre a contratransferência se torna mais clara. Vale destacar, na íntegra, esta passagem:

O problema da contratransferência, que o senhor suscita, é um dos mais difíceis da técnica psicanalítica. Na teoria, segundo penso, é mais fácil de resolver. $\mathrm{O}$ que se dá ao paciente não deve ser jamais afeto espontâneo, mas sempre deve ser afeto conscientemente manifesto, em maior ou menor quantidade, conforme as necessidades do momento. Em certas circunstâncias, é preciso dar muito - nada, porém, que venha diretamente do inconsciente do analista. Para mim, esta é a regra (Freud \& Binswanger, 1995: 183).

Freud assevera - considerando uma falta técnica o não cumprimento desta regra - que o analista nunca deve expressar seu afeto de forma direta. Prescreve como única possibilidade de expressão afetiva do analista aquela que é precedida por um processo psíquico consciente, o que parece implicar um trabalho psíquico de elaboração (Freud \& Binswanger, 1995).

Entretanto, reconhece a dificuldade de se lidar tecnicamente com a contratransferência. Esta questão, segundo ele, é mais facilmente solucionada no campo teórico do que na clínica. No âmbito da teoria, resolve o problema fazendo uma distinção entre "afeto espontâneo" e "afeto conscientemente manifesto" (Freud \& Binswanger, 1995: 183). O primeiro é encarado como erro técnico. Já o segundo, a única via possível para o analista expressar seu afeto no processo psicanalítico. Esta distinção também pode ser descrita em outros termos: como uma oposição entre atuação contratransferencial e a contratransferência sujeita ao processo de elaboração.

A atuação da contratransferência parece ser uma das razões que teriam levado Freud a formular a regra de abstinência ([1914-1915] 1980; [1918-1919] 1980). Esta regra tanto se dirige ao analisando como ao analista. Segundo este princípio, o analista deveria estar atento para o risco de, ao se deixar levar por sentimentos em 
relação ao paciente, "subitamente ir mais além" (Freud, [1914-1915] 1980: 214) do que havia pretendido. Trata-se do risco de responder às demandas do paciente em análise e, mesmo, de responder aos próprios desejos frente a tais demandas. Esta possibilidade de ir mais além parece remeter, mais precisamente, à atuação contratransferencial. $\mathrm{O}$ caminho para que o analista não incorra numa atuação dentro da situação de análise seria o da abertura para a via da elaboração - trabalho psíquico que, como será indicado mais adiante, se ilustra através da expressão "lidar com" (Hanns, 1996: 179).

A elaboração da contratransferência é o modo pelo qual o analista poderia conduzir seu afeto no sentido de uma simbolização, isto é, em um caminho em direção à palavra, dando-lhe sentido através do desenvolvimento de redes fantasmáticas, impedindo que venha a emergir no campo do ato. Trata-se, portanto, da aposta em um processo de elaboração e simbolização contínuo, através do qual seja possível reconhecer e nomear suas impressōes afetivas.

Vale sublinhar, contudo, que a análise das postulações de Freud a respeito da contratransferência não parece indicar, a princípio, que ele teria recomendado diretamente a elaboração da contratransferência. Sua recomendação ganha o caráter de perigo a ser dominado quando se referia explicitamente ao conceito de contratransferência de forma mais evidente. Esta recomendação estaria associada à obrigatoriedade da análise pessoal do analista - associação que não deixa de ser um modo oblíquo de indicar a elaboração da contratransferência. Todavia, veremos que tal prescrição é feita de forma direta no texto freudiano. Para defender nossa hipótese, recorreremos a um breve exercício de hermenêutica. Este exercício vai nos reconduzir à questão do que significava, para Freud, a necessidade de sobrepujar a contratransferência.

\section{O SENTIDO DE BEWÄLTIGEN}

O texto freudiano em português não torna muito evidente o significado preciso da prescrição freudiana que recomenda o sobrepujamento da contratransferência. Ideia enigmática essa, a de sobrepujar a contratransferência. Entre os significados apresentados no Dicionário Aurélio (Ferreira, 1975) para o termo "sobrepujar", vale destacar as seguintes: (1) ultrapassar; (2) passar por cima de, (3) dominar. Para cada uma destas acepções são apresentadas citações que têm a função de ilustrar o significado indicado. Em relação ao termo ultrapassar, segue-se a citação: "Nosso poderio sobrepuja o das tropas inimigas". Para a expressão passar por cima de, a frase: 
"Sua coragem sobrepuja todos os perigos". E, quanto ao termo dominar, a passagem: “O lutador sobrepujou facilmente o adversário" (Ferreira, 1975: 1313).

Não podemos deixar de notar que as citações utilizadas têm um conteúdo similar: o de uma luta contra os perigos; um combate contra os inimigos. Conteúdo que transmite a imagem de um espaço de guerra. Nesta perspectiva, o movimento de sobrepujar parece ter o sentido de eliminar o objeto ao qual ele se dirige, passando por cima deste adversário, derrotando-o nesta batalha.

As imagens evocadas pelas frases acima citadas são, sem dúvida, significativas. Elas indicam que a leitura da prescrição freudiana pode incidir na fixidez de uma única interpretação: a de tomar o fenômeno contratransferencial como algo a ser abolido do espaço analítico. Leitura que nos parece equivocada.

Para esclarecer este ponto, faremos uma pequena digressão. É notória a crítica, no campo psicanalítico, com relação à tradução brasileira das Obras completas de Freud. Como se sabe, as Obras completas publicadas no Brasil entre 1970 e 1977 não foram traduzidas diretamente do alemão, mas do inglês, da Standard Edition elaborada por James Strachey. A própria tradução de Strachey já tinha sido objeto de críticas contundentes, sobretudo pelo apagamento do estilo literário de Freud em prol de um vocabulário mais científico. Quanto à tradução brasileira, somam-se outras críticas, tal como a do emprego de termos excêntricos, cuja escolha só se explica pela proximidade sonora dos termos correspondentes em inglês (Hanns, 2003; Roudinesco \& Plon, 1997). Desta maneira, o leitor brasileiro, mais do que o de outras nacionalidades, está sujeito a essas inevitáveis perdas de tradução. Em virtude disso, propomos um retorno ao texto original de Freud a fim de dar mais clareza à sua recomendação quanto ao fenômeno contratransferencial.

$\mathrm{Na}$ passagem supracitada do artigo "As perspectivas futuras da terapêutica psicanalítica" ([1910a] 1980), o termo em alemão que veio a ser traduzido na Edição Standard Brasileira por "sobrepujar" é bewältigen (Freud, [1910b] 1989: 126). Este termo suscita uma interessante discussão no Dicionário comentado do alemão de Freud (1996), de autoria de Luiz Alberto Hanns. Neste dicionário são apresentados vários termos em alemão, empregados por Freud, que causam alguma estranheza em português. Entre eles, encontramos o termo bewältigen, com relação ao qual o autor sugere as conotações mais apropriadas ao campo linguístico germânico.

A propósito deste verbo, Hanns afirma que dominar é o termo em português pelo qual a palavra alemã foi mais frequentemente traduzida na Edição Standard Brasileira. Segundo ele, este termo se apresenta no texto psicanalítico quando se discute a questão da atividade do aparelho psíquico ao se deparar com as excitações pulsionais. No entanto, o emprego de bewältigen não se restringe, como vimos, 
a este contexto teórico. Freud ([1910b] 1989) o utiliza também para se referir especificamente à atividade do analista diante da contratransferência.

Ao comparar o significado de bewältigen com o do termo em português dominar, Hanns (1996) indica que os significados de dominar-que contemplam as ações de subjugar, manter o controle, refrear - não correspondem de forma alguma ao termo em alemão. Segundo o autor, entre os diversos significados do termo em alemão, a tradução que considera mais apropriada seria aquela que comporta a ideia de "digerir, elaborar, absorver, superar emocionalmente" (Hanns, 1996: 176).

Com isto, o autor pretende mostrar que ao se traduzir bewältigen por "dominar" - e, poderíamos acrescentar, por "sobrepujar" - "perde-se a ênfase no sentido de uma ação que visa lidar com uma situação avassaladora e superá-la” (Hanns, 1996: 179, grifo dos autores). Ao se referir à questão das exigências pulsionais no texto freudiano, o autor expressa claramente sua preferência pelo significado de "lidar com", por indicar "um tipo de domínio que descreve uma tentativa de lidar com algo de maior porte" (Hanns, 1996: 181), mas que não implica o emprego de autoridade e força a fim de regular e refrear certo fenômeno.

A partir destas considerações hermenêuticas, podemos retomar a questão da contratransferência a fim de propor outro enfoque com relação a este tema. Se, ao invés dos termos "sobrepujar" ou "controlar", traduzíssemos bewältigen para algo mais próximo de um "lidar com”, a mudança de enfoque já traria uma nova possibilidade de se encarar a questão contratransferencial na clínica psicanalítica. A conotação de "lidar com" sugere um modo de se conceber o manejo da contratransferência bem distinto daquele a que nos referimos anteriormente. Longe de indicar uma supressão ou eliminação deste fenômeno na experiência psicanalítica - tal como a tradução de Strachey dá a entender -, Freud ([1910a] 1980) parece sustentar um ponto de vista menos categórico e, ao mesmo tempo, mais nuançado a respeito do fenômeno contratransferencial.

Um manejo da contratransferência que tenha em vista esse movimento de "lidar com" não pretende suprimir no analista todo vestígio de afetividade emergente na situação transferencial. Ao contrário, trata-se sim de "digerir, elaborar, absorver" (Hanns, 1996: 176) o afeto. Deste modo, a recomendação freudiana parece dizer mais respeito à exigência de lidar com, de elaborar a contratransferência.

Não podemos deixar de reconhecer que, nas formulações de Freud relativas ao conceito, o que salta aos olhos é sua constante advertência quanto ao perigo representado pelas respostas contratransferenciais na situação analítica, o que teria contribuído para a visada negativa do conceito. Talvez seja esta a principal justificativa para que se interprete a posição freudiana como a de defensor da objetividade e assepsia psíquica do analista. No entanto, a despeito disso, é possível considerar 
que ele apostava, sim, na afetividade do analista como aliada ao trabalho analítico. Diante do afeto, Freud parece propor ao analista um trabalho de elaboração.

\section{CONSIDERAÇÕES FINAIS}

Como pudemos observar, o texto freudiano apresenta indícios que revelam a importância da afetividade do analista no manejo clínico, o que indica o reconhecimento da irremediável implicação afetiva do analista no processo de análise. Mesmo que uma concepção intelectualista ganhe destaque em alguns momentos no texto freudiano, ela não designa um posicionamento unívoco em Freud. Se, por um lado, os alertas quanto ao perigoso terreno da contratransferência e a metáfora do cirurgião servem para reforçar a aparente certeza de que o analista só poderia exercer sua função a partir de uma posição caracterizada pela objetividade e racionalidade, por outro, o posicionamento de Freud sobre a questão dos afetos do analista não é tão simples de se delinear.

Ao invés de sustentar, de modo exclusivo, a objetividade da função analítica, Freud desenvolve seu pensamento de forma bem mais complexa. Ao lado da prescrição de objetividade, Freud reconhece, mais de uma vez, que é inevitável ao analista implicar-se afetivamente no processo de análise. Tanto na regra da atenção flutuante como no artifício técnico da construção em análise, ele nos mostra que os afetos do analista não podem ser excluídos do espaço analítico.

Do mesmo modo, notamos que a contratransferência não se configura por si mesma, no texto freudiano, como um risco para a condução do tratamento. Sendo este fenômeno uma condição inerente da escuta analítica, há que se encontrar uma maneira de lidar com ela. A elaboração da contratransferência se delineia, assim, como resposta a este embaraço teórico do texto freudiano. A atuação contratransferencial, por sua vez, pode ser articulada com o perigo a que Freud aludia.

Sendo assim, embora muito se fale atualmente sobre o ineditismo de autores pós-freudianos, sensíveis à afetividade circulante entre analista e analisando no espaço analítico, há que ressaltar o fato de que Freud sempre esteve atento para este aspecto central da escuta analítica. Certamente não concedeu à afetividade do analista um lugar capital no manejo clínico, como fizeram alguns de seus seguidores. Mas também não há uma distância tão radical entre seu posicionamento e o de autores como Ferenczi e Winnicott. Muitas das formulações destes autores, no que diz respeito ao privilégio dado aos afetos do analista na condução clínica, devem sua fonte à obra freudiana. 


\section{REFERÊNCIAS}

Ferreira, A. B. H. (1975). Novo dicionário Aurélio. Rio de Janeiro: Nova Fronteira.

Freud, S. (1905/1980). Fragmento da análise de um caso de histeria. Obras completas, ESB, v. VII. Rio de Janeiro: Imago.

Freud, S. (1910a/1980). As perspectivas futuras da terapêutica psicanalítica. Obras completas, $E S B$, v. XI. Rio de Janeiro: Imago.

Freud, S. (1910b/1989). Die zukünftigen Chancen der psychoanalytischen Therapie. In: Studienausgabe Ergänzungsband: Schriften zur Behandlungstechnik. Frankfurt AM Main: S. Fischer Verlag.

Freud, S. (1912/1980). Recomendações aos médicos que exercem a psicanálise. Obras completas, ESB, v. XII. Rio de Janeiro: Imago.

Freud, S. (1914-1915/1980). Observaçôes sobre o amor transferencial (Novas recomendações sobre a técnica da psicanálise III). Obras completas, ESB, v. XII. Rio de Janeiro: Imago.

Freud, S. (1918-1919/1980). Linhas de progresso na terapia psicanalítica. Obras completas, $E S B$, v. XVII. Rio de Janeiro: Imago.

Freud, S. (1920/1980). Além do princípio do prazer. Obras completas, ESB, v. XVIII. Rio de Janeiro: Imago.

Freud, S. (1937a/1980). Construções em análise. Obras completas, ESB, v. XXIII. Rio de Janeiro: Imago.

Freud, S. (1937b/1980). Análise terminável e interminável. Obras completas, ESB, v. XXIII. Rio de Janeiro: Imago.

Freud, S., \& Binswanger, L. (I995). Correspondance 1908-1938. Paris: Calmann-Lévy.

Gondar, J. (2008). Além da contratransferência: os afetos do analista. Cadernos de Psicanálise-CPRJ, 21, 175-191.

Hanns, L. A. (1996). Dicionário comentado do alemão de Freud. Rio de Janeiro: Imago.

Hanns, L. A. (2003). Uma nova tradução brasileira das obras de Freud. Estados Gerais da Psicanálise: Segundo Encontro Mundial. Rio de Janeiro. Retirado de <www.estadosgerais.org >.

Roudinesco, E., \& Plon, M. (1997). Dicionário de psicanálise. Rio de Janeiro: Jorge Zahar.

Schneider, M. (1993). Afeto e linguagem nos primeiros escritos de Freud. São Paulo: Editora Escuta.

Viderman, S. (1990). A construção do espaço analítico. São Paulo: Editora Escuta. 


\section{Notas}

1 Convém esclarecer que a noção de afeto implica duas acepções distintas. Esta distinção é assinalada por Schneider (1993) ao se referir a duas modalidades de afeto: a impressão e a expressão afetiva. A primeira modalidade, a impressão afetiva, diz respeito ao afeto em estado bruto, ou seja, a experiência de ser afetado. Já a expressão afetiva pode ser entendida como uma gradação do afeto, isto é, quando se dão os primeiros esforços para traduzir essa experiência, permitindo que o afeto se encaminhe para o campo representacional. Neste caso, trata-se dos afetos em sua dimensão qualitativa, ao contrário da impressão afetiva, que remete ao registro intensivo.

2 Freud indica que o trabalho de construção, realizado pelo analista, "constitui apenas um trabalho preliminar" ([1937a] 1980: 294). Trata-se, na verdade, de dar o empurrão para que o paciente possa fazer, por si mesmo, sua reconstrução. A construção efetuada pelo analista só teria valor se o paciente, a partir dela, produzisse novas associaçóes que dessem continuidade ao trabalho de análise.

Recebido em 12 de abril de 2010 Aceito para publicação em 28 de janeiro de 2011 